\title{
Botulinum neurotoxin type-A when utilized in animals with trigeminal sensitization induced a antinociceptive effect
}

\author{
Neurotoxina botulínica do tipo-A quando utilizada em animais com sensibilização \\ trigeminal induz efeito antinociceptivo \\ Elcio J Piovesan ${ }^{1,2}$, Michael Oshinsky³, Stephen Silberstein ${ }^{3}$, Pedro Andre Kowacs' ${ }^{1}$ Edison Matos Novak', \\ Lineu Cesar Werneck ${ }^{1}$
}

\begin{abstract}
Purpose of the study was evaluate the possible antinociceptive effect of botulinum neurotoxin type-A (BoNT/A) in an experimental model of trigeminal neuralgia. Method: Neuropathic pain was induced by surgical constriction of the infraorbital nerve in rats. A control group underwent a sham procedure consisting of surgical exposure of the nerve. Subgroups of each group received either BoNT/A or isotonic saline solution. The clinical response was assessed with the $-20^{\circ} \mathrm{C}$ test. Animals that underwent nerve constriction developed sensitization; the sham group did not. Results: The sensitization was reversed by BoNT/A treatment evident 24 hours following application. Pronociceptive effect was observed in the sham group following BoNT/A. Conclusion: BoNT/A has an antinociceptive effect in sensitized animals and a pronociceptive effect in non-sensitized animals.
\end{abstract}

Keywords: analgesics; botulinum toxins; facial pain; trigeminal neuralgia.

\section{RESUMO}

A proposta do estudo foi avaliar o efeito antinociceptivo da neurotoxina botulínica do tipo A (BoNT/A) em um modelo experimental de nevralgia trigeminal. Método: O grupo estudo foi obtido através da constrição do nervo infraorbital em ratos e o grupo controle pela simples exposição deste nervo. Cada um dos grupos foram subdivididos de acordo com o tratamento realizado após a intervenção cirurgica: solução salina isotônica ou BoNT/A. A resposta terapêutica foi avaliada através do teste de $-20^{\circ} \mathrm{C}$. Resultados: Animais com constrição do nervo desenvolveram uma sensibilização nociceptiva quando comparados ao grupo controle. Ela foi revertida após 24 horas utilizando BoNT/A. $O$ efeito pronociceptivo foi observado no grupo controle após a administração de BoNTA. Conclusão: BoNT/A apresenta um efeito antinociceptivo em animais sensibilizados e pronociceptivo em animals não sensibilizados.

Palavras-chave: analgésicos; toxinas botulínicas; dor facial; nervo infraorbital; neuralgia do trigêmeo.

Trigeminal neuralgia (TN) is a rare and severe pain syndrome affecting the area innervated by one or more branches of the trigeminal nerve, usually starts in the second or third division ${ }^{1}$. The pain is unilateral characterized by brief electric shock-like (lasting a second to 2 minutes), abrupt is onset and termination ${ }^{1 .}$ Generally evoked by trivial stimuli including washing, shaving, smoking, talking and/or brushing the teeth ${ }^{1}$. TN is divided into classical neuralgia trigeminal and painful trigeminal neuropathy, being the first idiopathic or caused by compression of the trigeminal root by tortuous or aberrant vessels and the latter secondary to an identificable cause such as multiple sclerosis ${ }^{1}$. The pain mechanism hypothesized in either type of TN is due to structural changes affecting the $A \delta$ afferent fibers resulting in demyelination, production of ephatic potentials and neuronal hyperexcitation ${ }^{2}$.

Classical trigeminal neuralgia is usually responsive, at least initially, to pharmacotherapy. With the evolution of this disorder may reduce initial response, there is a need to increase the dosages and combination therapies. Over time

1 Universidade Federal do Paraná, Hospital das Clínicas, Serviço de Neurologia, Curitiba PR, Brasil;

${ }^{2}$ Universidade Federal do Paraná, Departmento de Ciências da Saúde, Laboratório Experimental, Curitiba PR, Brasil;

${ }^{3}$ Thomas Jefferson University, Jefferson Headache Center, Philadephia PA, USA.

Correspondence: Elcio Juliato Piovesan, Serviço de Neurologia, Departamento de Medicina Interna, Hospital de Clínicas, Universidade Federal do Paraná; Rua General Carneiro 181; 800060-900 Curitiba PR, Brasil.E-mail: piovesan1@hotmail.com

Conflict of interest: There is no conflict of interest to declare.

Support: The study was supported by the Coordenção de Aperfeiçoamento de Pessoal de Nivel Superior (CAPES).

Received 06 October 2015; Received in final form 05 March 2016; Accept 01 April 2016 
side effects may arise or therapeutic effect loses its consistency. This is the perfect setting for surgical treatment. Surgical treatment options consist on procedures dealing controlled damage to trigeminal fibers or the Gasserian ganglion; or microvascular decompression. Surgical procedures are reserved for patients with disease refractory to drug therapy (which occurs approximately $30 \%$ of the time) or patients who initially responded but later became intolerant to medical therapy ${ }^{3}$

Pharmacotherapy includes mainly agents used to control neuropathic pain such as carbamazepine, oxcarbazepine, baclofen, lamotrigine and pimozide 4 . In refractory cases of surgical and drugs therapy such as Botulinum Neurotoxin Type A (BoNT/A) may be a therapeutic option.

The BoNT/A is currently used to treat numerous medical conditions, including hyperactive skeletal-muscular disorders and pain. The analgesic effect of BoNT/A has been showed in animal experiments models of neuropathic pain over the sciatic nerve that were constriction injury procedure ${ }^{6,7,8,9}$ and infraorbital nerves ${ }^{8,10}$. In humans we did an open study of BoNT/A found it was effective in treating $\mathrm{TN}^{11}$. Recently a double-blind, placebo-controlled trial showed that BoNT/A is more efficient and safe than isotonic saline solution in treating $\mathrm{TN}^{12}$. Althought in other studies that utilized BoNT/A for chronic migraine treatment showed a positive therapeutic effect and paradoxically this patients showed side effects such as pain symptoms ${ }^{13}$. This includes pronociceptive effects (neck pain; headache, myalgia and musculoskeletal pain greather than placebo group $)^{13}$.

Thus clinical and preclinical studies have shown that BoNT/A can produce dual sensory responses. The aim of our study was to evaluate and understand the mechanisms involved in pronociceptive and antinociceptive effect of BoNT/A in an experimental model of TN utilizing the Infraorbital nerve constriction.

\section{METHOD}

\section{Subjects}

Experiments were conducted in male Norvegicus rats ( $\mathrm{n}=89$ ) weighing 140-200 g. Groups of four animals were housed four in a cage at $22 \pm 1^{\circ} \mathrm{C}$ with a 12-hour light/dark cycle (lights on at 07:00 a.m.) and free access to food and water except during the test periods. All experiments and experimental procedures were conducted with the approval of the local ethics committee for research on animals).

Eighty-nine animals were allocated to the study. Fifty animals were excluded based on their baseline thermal nociceptive response (TNR) (48 scored less than four seconds and two animals scored higher than $14 \mathrm{sec}$ ). Of the 39 remaining animals, 24 and 15 were randomly placed into the active and sham groups, respectively. Of the 24 animals selected for nerve constriction, eight were excluded because they failed to show cold sensitization. The 16 remaining animals were then divided equally between botulinum toxin group (BoNT/A) (Group 1) and isotonic saline solution group (ISS) (Group 2). Of the 15 animals in the sham group, seven and eight rats were allocated to the BoNT/A (Group 3) and ISS (Group 4) treatments, respectively (Figure 1).

\section{Phases of the study}

The study consisted of a 21 day run-in period. During this time, three behavioral tests were done that evaluated facial nociception using cold stimulation testing (CST) (the $-20^{\circ} \mathrm{C}$ test). This determined their thermal nociceptive response (TNR) (the time spent performing facial cleaning movements) baseline score (Figure 1). As suggested in previous work any animal that scored less than 4 or more than $14 \mathrm{sec}$ was excluded because pain behavior was outside expected limits ${ }^{14,15}$. The animals were then divided into two groups: an experimental group that underwent left infraorbital nerve (ION) constriction, and a sham group that underwent ION exposure but not nerve constriction. Both groups were assessed by the CST four and six days after surgery. Only rats in the active group whose TNR score increased by at least $45 \%$ relative to baseline remained in the study. This increase in scores featuring a nociceptive sensitization ${ }^{16,17}$. No animals in the sham group were excluded (none experienced sensitization). On post-surgery day six, the animals were subdivided into four groups: Group 1 - constriction treated with BoNT/A (BoNT/A-C); Group 2 - constriction treated with isotonic saline solution $0.9 \%$ (ISS-C); Group 3 - sham surgery treated with BoNT/A (BoNT/A-S); and Group 4 - sham surgery treated with ISS (ISS-S). The animals were evaluated by the CST test six, 24, 48, 72, and 96 hours after treatment. Post-surgery day six was the baseline of the study.

\section{Cold stimulation test (CST or $-20^{\circ} \mathrm{C}$ test)}

This protocol was performed according the standard of previous studies ${ }^{14,15}$. The animals were placed in an observation box $(\mathrm{WxLxH}=30 \times 34 \times 30 \mathrm{~cm})$ for $30 \mathrm{~min}$ to habituate them. Tetrafluoroethane spray (1 second of exposure) was applied to the left ION emergence. The spray was projected onto the ION emergence using a tube driver positioned a few millimeters away to avoid releasing the spray onto the animals' eyes. The rat was observed for two minutes; the time (in seconds) spent on bilateral synchronous or unilateral independent facial cleaning movements (i.e., grooming) was recorded. Each animal was tested twice, and the average for both test scores was considered to be its TNR (cold). To confirm that the temperature from the stimulus was $-20^{\circ} \mathrm{C}$, a group of animals was examined immediately after the spray with a surface thermometer, as previously described for other studies ${ }^{15}$. 


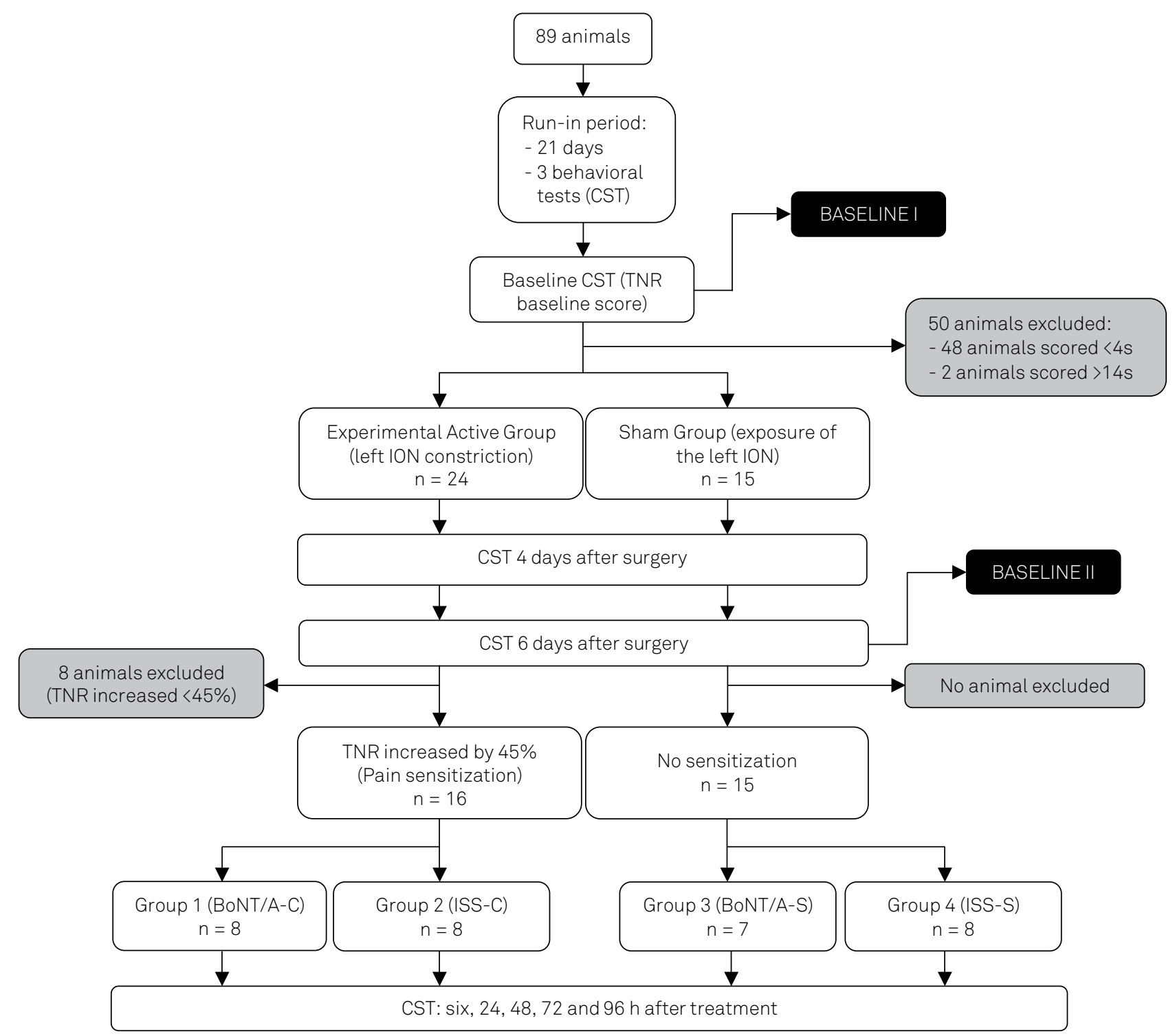

Figure 1. Study design. CST: cold stimulation test; TNR: thermal nociceptive response; ION: infraorbital nerve; BoNT/A-C: group of animals subjected to constriction of the infraorbital nerve and treated with Onabotulinumtoxin-A; ISS-C: group of animals which underwent constriction of the infraorbital nerve and treatment with normal saline 0.9\%; BoNT/A-S: group of animals which underwent only exposure of the nerve - sham procedure - and treated with Onabotulinumtoxin-A; ISS-S: group of animals subjected to nerve exposure and treated with isotonic saline solution.

\section{Surgery}

The animals were anesthetized with a mixture of ketamine $(50 \mathrm{mg} / \mathrm{kg})$ and xylazine $(10 \mathrm{mg} / \mathrm{kg})$ injected intraperitoneally five to ten minutes prior to the surgical constriction or exposure of the ION. The procedure to constrict the left ION has been previously described ${ }^{14,15}$. Briefly, the skin under the left eye was incised approximately $3 \mathrm{~mm}$ caudal to the myofascial pads. The muscles in this region (the superior lip elevator and anterior superficial masseter muscles) were dissected to expose the ION. During the procedure, the nerve was continuously irrigated with ISS $0.9 \%$. Two silk 4-0 ligatures spaced $2 \mathrm{~mm}$ apart were then tied loosely around the ION and the incision was closed with 4-0 sutures. Animals in the sham group underwent the same procedure, with the exception of ION ligation. The animals were kept in the surgery room until they fully recovered.

\section{Drugs and doses}

BoNT/A or ISS was injected on post-surgery day six into the area of nerve ligation. A syringe with an ultrafine $5 / 16$ " needle $(30-\mathrm{G} / 8 \mathrm{~mm} / 0.3 \mathrm{~mm})$ was used for the injections. The BoNT/A used was Botox (Allergan, Inc., Irvine, CA, USA). Vials containing 100 mouse units were reconstituted with $2 \mathrm{ml}$ of ISS $0,9 \%$ (final concentration: 50 mouse units $/ \mathrm{ml}$ ). The BoNT/A dosage was 15 units $/ \mathrm{Kg}$ $(30 \mu \mathrm{l} / \mathrm{Kg}$ ); rats in the ISS groups received $30 \mu \mathrm{l} / \mathrm{Kg}$ of isotonic saline solution 0,9\% (ISS). The dose of BoNT/A used 
in this study ( $\sim 3$ units) was based on previous studies ${ }^{16}$. All animals received only one treatment.

\section{Baseline groups}

The study used two times of baseline: Baseline I - related to the initial phase of the study, where all the animals were submitted to TNR with no intervention (surgery to therapeutic intervention). This phase was called Naive Baseline phase. This phase was used to evaluate the sensitizing potential of the method (infraorbital nerve constriction). Baseline II - period after surgery constriction nerve or exposure to evaluate the analgesic effect of BoNTA or pronociceptive called Baseline Post-Surgery Phase (Figure 1).

\section{Evaluation of motor activity}

A possible influence of BoNT/A on motor activity in this model of the study was previously evaluated utilizing The Open Field Test; it did not produce interference ${ }^{17}$.

\section{Blinding of the investigators}

The researcher who applied the drugs did not participate in any other phase of this study (EMN). The investigator did not know which animals belonged to the active or sham groups. The values of the CST were correlated with their respective groups only at the end of the study.

\section{Statistics}

For comparations variables we utilized mean and median. For measures of dispersion we utilized standart deviation (sd). Statistical analysis was performed using one-way Analysis of Variance and Analysis of Variance for Repeated Measures and (LSD) test for multiple comparisons. The data are expressed as percentage of baseline. For all tests, p-values less than 0.05 were considered significant.

\section{RESULTS}

\section{Group comparison over the Baseline I}

All animals of the four subgroups in the baseline I phase showed the similar TNR $(p=0,326)$. These results show that all animals showed the same pattern nociceptive experimental interventions before the intervention procedures (Table 1).

\section{Group comparasion over the Baseline II (Sensitization phase)}

The evaluation of TNR 6 days post-surgical treatment in four groups showed a statistically significant difference $(\mathrm{p}<0,001)$ (Table 1). The groups were subjected to constriction nerve were also sensitized $(p=0.070)$ in the same manner as the sham group were also desensitized $(p=0.823)$ (Table 2). All comparisons between groups have undergone constriction and sham groups were statistically significant $(\mathrm{p}<0,001)$ (Table 2). The results demonstrate that the technique utilized (constriction of the infra-orbital nerve) was effective to induce a state of sensitization (peripheral neuropathy infra-orbital nerve). The various comparisons are shown in (Table 2).

\section{Group comparison after the treatment}

The comparison of the percentage changes of values from baseline II after the treatment found that at all times (six, 24, 48, 72, and 96 hours post-treatment) and groups the TNR score varied significantly (Table 3 ). The BoNT/A-C group showed a TNR reduction beginning six hours after treatment and maintaining this reduction 24 , 48, and 72 hours after treatment. The ISS-C group showed a slight TNR decrease at six hours, followed by an increase in the TNR values at 24, 48, 72, and 96 hours, suggesting a conservation of sensitization. The BoNT/A-S group showed an increase in TNR values at six, 24, 48, 72 , and 96 hours suggesting a pronociceptive effect (Table 3 ). The ISS-S group showed a decrease in TNR values at six, 24, 48, and 72 hours (Table 3 ).

\section{$2 \times 2$ Group comparisons at different times}

The comparison of the percentage changes of values from baseline II after the treatment when 2X2 group comparisons found that at all times the BoNT/A-C subgroup had evidence of antinociception compared with the ISS-C group 24 hours after treatment (Table 3 ). At other times,

Table 1. Comparison between the subgroups in relation to the time baseline I and II.

\begin{tabular}{|c|c|c|c|c|c|c|c|c|}
\hline & Subgroups & $\mathrm{N}$ & Average & Median & Minimum & Maximum & SD & $p$-value* \\
\hline \multirow{4}{*}{ Baseline I } & BoNTA-C & 8 & 6.3 & 6.3 & 4.1 & 8.9 & 1.8 & \\
\hline & ISS-C & 8 & 7.5 & 7.8 & 4 & 10 & 2.3 & \\
\hline & BoNTA-S & 7 & 8.7 & 9 & 4.1 & 14 & 3.8 & \\
\hline & ISS-S & 8 & 8.5 & 7.7 & 4.7 & 14 & 3.2 & 0,326 \\
\hline \multirow{4}{*}{ Baseline II } & BoNTA-C & 8 & 20 & 20.2 & 10.4 & 25.6 & 5.1 & \\
\hline & ISS-C & 8 & 16.5 & 16.3 & 12 & 19.9 & 2.4 & \\
\hline & BoNTA-S & 7 & 6.4 & 7.7 & 1 & 12.6 & 4.7 & \\
\hline & ISS-S & 8 & 6.8 & 6.9 & 4 & 10.6 & 2.2 & $<0,001$ \\
\hline
\end{tabular}

BoNTA-C: constriction treated with BoNT/A; ISS-C: constriction treated with isotonic saline solution 0.9\%; BoNTA-S: sham surgery treated with BoNT/A; ISS-S: sham surgery treated with isotonic saline solution $0.9 \%$; * One-way ANOVA, $p<0,05$. 
Table 2. Relationship between subgroups in phase II baseline.

\begin{tabular}{lc}
\hline Groups under comparison & p-value* \\
\hline BoNTA-C x ISS-C & 0.07 \\
BoNTA-C x BoNTA-S & $<0.001$ \\
BoNTA-C x ISS-S & $<0.001$ \\
ISS-C x BoNTA-S & $<0.001$ \\
ISS-C $\times$ ISS-S & $<0.001$ \\
BoNTA-S $\times$ ISS-S & 0.823 \\
\hline
\end{tabular}

BoNTA-C: constriction treated with BoNT/A; ISS-C: constriction treated with isotonic saline solution 0.9\%; BoNTA-S: sham surgery treated with BoNT/A; ISS-S: sham surgery treated with isotonic saline solution $0.9 \%$;* Fisher LSD test, $p<0,05$.

this antinociceptive effect was not observed (six, 48, 72, and 96 hours). BoNT/A when utilized in animals without sensitization induce a pronociceptive behavior at all times (comparison between BoNT/A-S and ISS-S groups) (Table 3 and Figure 2). The TNR does not fluctuate significantly in animals subjected to treatment with ISS in the surgery or sham groups (Table 3 and Figure 2).

\section{DISCUSSION}

Our results showed that BoNT/A induces two distinct answers: antinociception effect over the animals that were sensitization state and pronociceptive effect over the animals without sensitization.

The analgesic or antinociceptive effect can be found in experimental or clinical studies. In animals BoNT/A reduces nociceptive behavior 24 hours after injection over sensitized nerves suggesting an analgesic effect ${ }^{9}$. Kitamura et al. demonstrated that unilateral infraorbital nerve constriction (IoNC) results in long-lasting (superior to 2 weeks) tactile allodynia associated with vesicle secretion of neurotransmitters from trigeminal ganglion ${ }^{18}$. The main neurotransmitters involved in the therapeutic effect of BoNT/A are substance $\mathrm{P}^{19}$ and CGRP ${ }^{20,21}$.The animals of Kitamura study were treated with intradermal BoNT/A and showed reduced immediate release vesicular of this neurotransmitters with consequent control of allodynia 11 days after treatment ${ }^{18}$. The differences of time results of this study and our results may be due to the different methodologies.

Probably peripheral injection of BoNT/A may affect neuropathic pain at the central level not only by an indirect effect but also through a direct action of axonal retrograde transport ${ }^{9}$. The BoNT/A after injection intra plantar reduce the allodynia in chronic constriction injury of the sciatic nerve ${ }^{4,6,7,8}$. This is a strong indication for the retrograde transport of peripherally injected BoNT/A. After treatment with peripheral injections of BoNT/A in chronic constrict injured sciatic nerve, cl-SNAP-25 (cellular membrane expression protein) was detected in spinal astrocytes. This is also an indication that BoNT/A may be transcytosed from nociceptive fibers in spinal cord and may enter into glial cells 9 . BoNT/A enters peripheral trigeminal nerve endings and later is axonally transported through the trigeminal ganglion to the spinal trigeminal nucleus ${ }^{6}$.

The IoNC accompanied by hyperalgesia and allodynia is used as a model of trigeminal neuropathy in rats ${ }^{14,15}$. We utilized this model because it can be used to assessment

Table 3. Group comparison after the treatment in different times.

\begin{tabular}{|c|c|c|c|c|c|c|c|c|}
\hline Time & Group & Valid N & Mean & Median & Minimum & Maximum & SD & $p$-value* \\
\hline \multirow{4}{*}{$6 \mathrm{~h}$} & BoNT/A-C & 8 & -53.31 & -53.81 & -76.88 & -18.37 & 20.14 & \\
\hline & ISS-C & 8 & -6.01 & -10.89 & -45.68 & 34.46 & 26.07 & \\
\hline & BoNT/A-S & 7 & 64.57 & 12.34 & -4.28 & 197.04 & 83.20 & \\
\hline & ISS-S & 8 & -15.18 & -35.59 & -79.15 & 114.24 & 59.63 & 0.002 \\
\hline \multirow{4}{*}{$24 \mathrm{~h}$} & BoNT/A-C & 8 & -44.94 & -42.03 & -91.49 & -9.22 & 25.15 & \\
\hline & ISS-C & 8 & 21.55 & 15.07 & -21.05 & 75.40 & 33.47 & \\
\hline & BoNT/A-S & 7 & 43.41 & 30.55 & -11.95 & 95.41 & 44.48 & \\
\hline & ISS-S & 8 & -13.21 & -18.09 & -75.28 & 61.89 & 38.59 & $<.001$ \\
\hline \multirow{4}{*}{$48 \mathrm{~h}$} & BoNT/A-C & 8 & -28.53 & -40.27 & -82.01 & 34.75 & 45.66 & \\
\hline & ISS-C & 8 & 28.62 & 21.94 & -17.76 & 80.95 & 39.65 & \\
\hline & BoNT/A-S & 7 & 202.83 & 72.36 & 14.61 & 819.47 & 286.21 & \\
\hline & ISS-S & 8 & 33.98 & -1.87 & -49.48 & 235.27 & 99.47 & 0.034 \\
\hline \multirow{4}{*}{$72 \mathrm{~h}$} & BoNT/A-C & 8 & -34.06 & -34.64 & -79.79 & 19.88 & 36.33 & \\
\hline & ISS-C & 8 & 51.35 & 42.48 & -3.65 & 153.27 & 54.40 & \\
\hline & BoNT/A-S & 7 & 166.19 & 174.15 & -4.81 & 449.56 & 148.74 & \\
\hline & ISS-S & 8 & -7.25 & -19.97 & -76.20 & 109.43 & 65.45 & 0.001 \\
\hline \multirow{4}{*}{$96 \mathrm{~h}$} & BoNT/A-C & 8 & 3.64 & -9.85 & -58.16 & 96.26 & 52.25 & \\
\hline & ISS-C & 8 & 23.24 & 28.36 & -36.76 & 66.41 & 32.84 & \\
\hline & BoNT/A-S & 7 & 284.75 & 101.47 & 12.56 & 854.87 & 307.86 & \\
\hline & ISS-S & 8 & 27.47 & 20.94 & -62.67 & 143.52 & 66.92 & 0.004 \\
\hline
\end{tabular}

SD: stantdard deviation; BoNTA-C: constriction treated with BoNT/A; ISS-C: constriction treated with isotonic saline solution 0.9\%; BoNTA-S: sham surgery treated with BoNT/A; ISS-S: sham surgery treated with isotonic saline solution 0.9\%; * One-way ANOVA, $p<0.05$. 


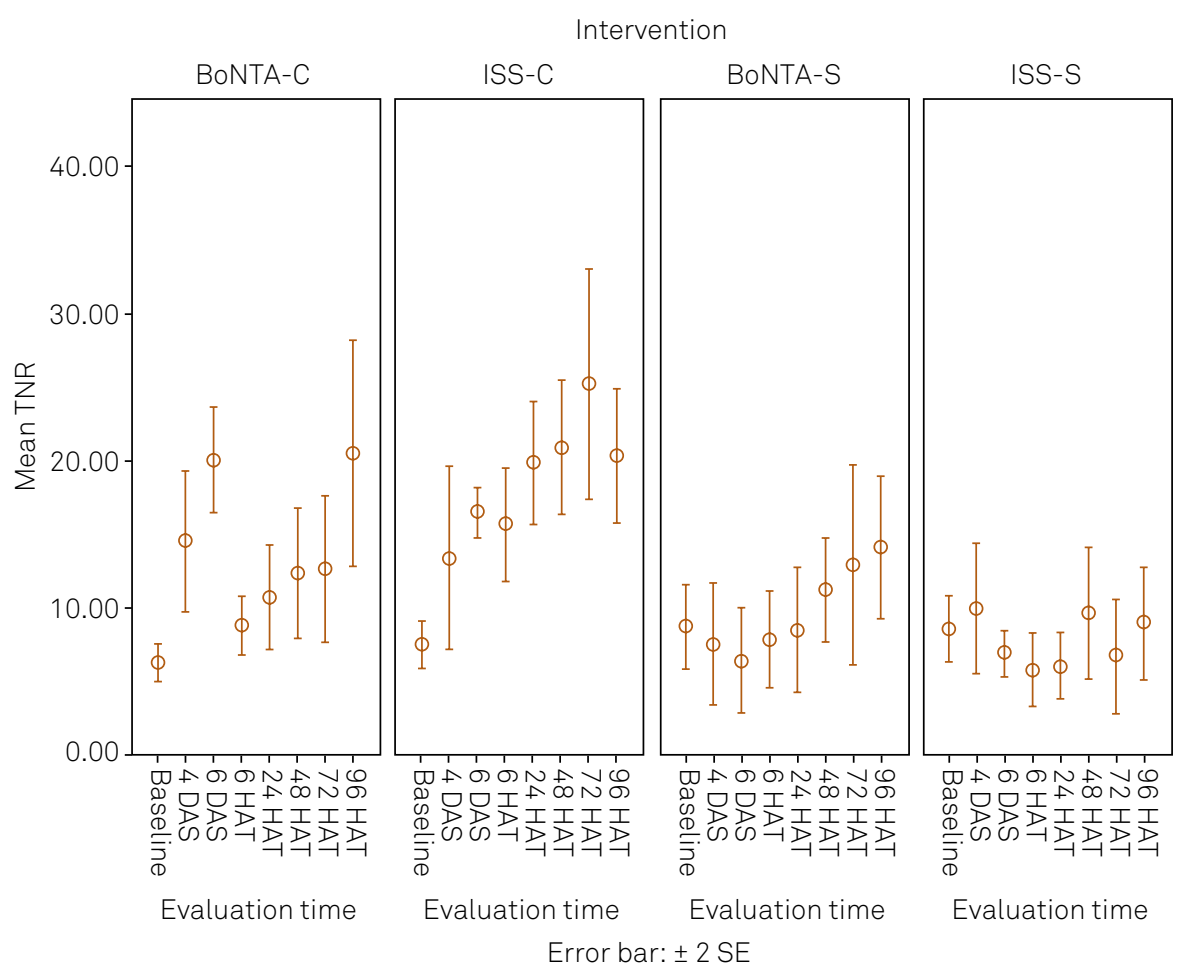

Figure 2. Distribution of the results in different moments and different groups: isotonic saline solution (ISS); onabotulinumtoxin type A (BoNT/A); sham (S); constrict (C); days after surgery (DAS); hours after treatment (HAT); thermal nociceptive response (TNR).

the therapeutic effects of future drugs in the trigeminal neuropathy treatment. Experiments showed that after the IoNC the animal's developed mechanical bilateral allodynia and dural extravasation of neurotransmitters. This was significantly reduced 2 and 3 days following the BoNT/A injection into the vibrissal pad ${ }^{10}$. Probably this analgesic effect occurs in central levels. When axonal transport blocker colchicine was injected ipsilateral to BoNT/A injection into the trigeminal ganglion, BoNT/A failed to reduce bilateral mechanical allodynia and dural neurogenic extravasation $^{10}$. Other studies utilized the IoNC models treated with BoNT/A corroborate for this observations ${ }^{10}$.

In our study the experimental model (ION ligation) produced a hypernociceptive state six days after surgery. The utilization of BoNT/A completely reversed this hypernociceptive state 24 hours post-injection (compared to saline) but it returned after 48 hours. Our results suggest that analgesic effect was limited to 48 hours.

\section{Clinical and experimental correlates in humans}

Several clinical studies demonstrate the antinociceptive effect of BoNT/A. In humans, intradermal injection of BoNT/A in the trigeminal nerve territory has been shown to reduce capsaicin-induced trigeminal pain. This injection lead also to a local reduction in both blood flow and skin temperature with peaked at the third and seventh days after the injection ${ }^{22}$. BoNT/A increased the perceived thermal thresholds but did not change the pressure threshold or perceived threshold for electrical stimuli. These findings suggest that BoNT/A acts on $\mathrm{C}$ fibers, in particular at their TRPV1 receptors ${ }^{22}$.

Patients with neuropathy and focal mechanical allodynia secondary to postherpetic neuralgia, trauma, or surgery reported a reduction of their allodynia within two to 14 weeks of intradermal BoNT/A application ${ }^{23}$. Patients with diabetic polyneuropathy who received intradermal injections of BoNT/A had improvement in pain four, eight and 12 weeks after treatment ${ }^{24}$. In a double-blind, placebo-controlled study of chronic migraine patients, BoNT/A was effective in reducing the number, frequency, and intensity of migraine attacks ${ }^{25}$.

We showed the analgesic effect of BoNT/A on primary stabbing headaches, a primary headache with ultra-short duration associated with migraine whose etiology is not fully understood and may be related to the sensitization of the trigeminal nerve ${ }^{26}$. In this study the patients were treated with intradermal injections of 12 units of BoNT/A. Using the follow-the-pain approach; clinical improvement was observed by seven days and lasted up to 60 days $^{26}$. In an open study of refractory trigeminal neuralgia, BoNT/A controlled the pain within a few days; the clinical response lasted approximately 60 days $^{11}$. The double blind placebo controlled study in trigeminal patients the BoNT/A inject over the pain symptoms territory showed superior results ${ }^{27}$.

Our findings support and add to previous experimental and clinical data. In experimental models, BoNT/A has an analgesic effect that starts within three hours and peaks at 24 hours (as our results) ${ }^{11}$. This initial analgesic effect 
is perhaps related to the blockade of vesicular traffic and alterations in synaptic receptors (TRPV1 and TRPA1) ${ }^{28}$. In initial conclusion, the analgesic (antinociceptive) effect of BoNT/A has been confirmed by data from this and from other studies.

\section{BoNT/A-induced pain (pronociceptive effect)}

BoNT/A may induce pain at the injection site and surrounding regions when used for some syndromes in which pain is not a frequent complaint (e.g. blepharospasm, cervical dystonia). In the PREEMPT program study, which evaluated the usefulness of BoNT/A in chronic migraine patients, toxin application in the cervical region induced local pain in $4.6 \%$ of subjects ${ }^{13}$. The pain was not related to muscle weakness; it began hours to days preceding the onset of motor weakness. Muscle weakness appeared in only $3.9 \%$ of the patients ${ }^{13}$. In episodic migraine patients treated with BoNT/A, neck pain occurred in $17.1 \%$ of the treated group versus $4.4 \%$ of the placebo group, a statistically significant difference ${ }^{29}$. One of the main differences between chronic migraine and episodic migraine is sensitization. The results of the literature clearly demonstrate that in subjects with headache lacking sensitization (episodic migraine) the side effect of BoNT/A was greater than patients with sensitization (chronic migraine) (17,1\% versus $4,6 \%$ respectively $)^{13,29}$. In cervicogenic headache, pain worsening occurred in $30 \%$ of patients treated with BoNT/A and $17 \%$ of those treated with placebo ${ }^{30}$.

In conclusion we showed that BoNT/A applied to a group of animals without sensitization the BoNT/A produced a pronociceptive pattern, making the animal more responsive to noxious stimuli (cold). Our second conclusion is that BoNT/A when utilized in animals with sensitization induced a antinociceptive effect.

Our study does not clarify the underlying mechanisms by which BoNT/A behaves as an antinociceptive and pronociceptive agent, but it demonstrates more clearly that the noxious state of the animals exposed to this substance will determine the pharmacologic profile. Perhaps the loss of the antinociceptive effect is due to the concomitant development of the pronociceptive effect.

\section{References}

1. Headache Classification Committee of the International Headache Society. The International Classification of Headache Disorders, 3 rd edition (beta version). Cephalalgia. 2013;33(9):629-808. doi:10.1177/0333102413485658

2. Truini A, Galeotti F, Cruccu G. New insight into trigeminal neuralgia. J Headache Pain. 2005;6(4):237-9. doi:10.1007/s10194-005-0195-9

3. Rozen TD, Capobianco DJ. Cranial neuralgias and other causes of facial pain. In: Silberstein SD, Lipton R, Dodick DW, editors. Wolff's Headache and other head pain. 8th ed. New York: Oxford:, 2008. p. 633-50.

4. Cruccu G, Gronseth G, Alksne J, Argoff C, Brainin M, Burchiel Ket al. AAN-EFNS guidelines on trigeminal neuralgia management. Eur J Neurol. 2008;15(10):1013-28. doi:10.1111/j.1468-1331.2008.02185.x

5. Marinelli S, Luvisetto S, Cobianchi S, Makuch W, Obara I, Mezzaroma E et al. Botulinum neurotoxin type A counteracts neuropathic pain and facilitates functional recovery after peripheral nerve injury in animal models. Neuroscience. 2010;171(1):316-28. doi:10.1016/j.neuroscience.2010.08.067

6. Matak I, Bach-Rojecky L, Filipović B, Lacković Z. Behavioral and immunohistochemical evidence for central antinociceptive activity of botulinum toxin A. Neuroscience. 2011;186:201-7. doi:10.1016/j.neuroscience.2011.04.026

7. Restani L, Novelli E, Bottari D, Leone P, Barone I, Galli-Resta L et al. Botulinum neurotoxin A impairs neurotransmission following retrograde transynaptic transport. Traffic. 2012;13(8):1083-9. doi:10.1111/j.1600-0854.2012.01369.x

8. Filipović B, Matak I, Bach-Rojecky L, Lacković Z. Central action of peripherally applied botulinum toxin type A on pain and dural protein extravasation in rat model of trigeminal neuropathy. PloS One. 2012;7(1):e29803. doi:10.1371/journal.pone.0029803

9. Marinelli S, Vacca V, Ricordy, Uggenti C, Tata A, Luvisetto S et al. The analgesic effect on neuropathic pain of retrogradely transported botulinum neurotoxin A involves Schwann cells and Astrocytes. PloS One. 2012;7(10):47977. doi:10.1371/journal.pone.0047977
10. Kumada A, Matsuka Y, Spigelman I, Maruhama K, Yamamoto Y, Neubert JK et. al. Intradermal injection of Botulinum toxin type A alleviates infraorbital nerve constriction-induced thermal hyperalgesia in an operant assay. J Oral Rehabil. 2012;39(1):63-72. doi:10.1111/j.1365-2842.2011.02236.x

11. Piovesan EJ, Teive HG, Kowacs PA, Della Coletta MV, Werneck LC, Silberstein SD. An open study of botulinum-A toxin treatment of trigeminal neuralgia. Neurology. 2005;65(8):1306-8. doi:10.1212/01.wnl.0000180940.98815.74

12. Wu CJ, Lian YJ, Zheng YK, Zhang HF, Chen Y, Xie NC et al. Botulinum toxin type $A$ for the treatment of trigeminal neuralgia: results from a randomized, double-blind, placebo-controlled trial. Cephalalgia. 2012;32(6):443-50. doi:10.1177/0333102412441721

13. Aurora SK, Winner P, Freeman MC, Spierings EL, Heiring JO, DeGryse RE et al.. OnabotulinumtoxinA for treatment of chronic migraine: pooled analyses of the 56-week PREEMPT clinical program. Headache. 2011;51(9):1358-73. doi:10.1111/j.1526-4610.2011.01990.x

14. Vos BP, Strassman AM, Maciewicz RJ. Behavioral evidence of trigeminal neuropathic pain following chronic constriction injury to the rat's infraorbital nerve. J Neurosci. 1994;14(5):2708-23.

15. Chichorro JG, Zampronio AR, Souza GEP, Rae GA. Orofacial cold hyperalgesia due to infraorbital nerve constriction injury in rats: reversal by endothelin receptor antagonists but non-steroidal anti-inflammatory drugs. Pain. 2006;123(1-2):64-74. doi:10.1016/j.pain.2006.02.010

16. Cui M, Khanijou S, Rubino J, Aoki KR. Subcutaneous administration of botulinum toxin A reduces formalin-induced pain. Pain. 2004;107(1-2):125-33. doi:10.1016/j.pain.2003.10.008

17. Piovesan EJ, Leite LS, Teive HG, Kowacs PA, Mulinari RA, Radunz V, et al. Botulinum toxin type-A effect as a preemptive treatment in a model of acute trigeminal pain: a pre-clinical double-blind and placebo-controlled study. Arq Neuropsiquiatr. 2011;69(1):56-63. doi:10.1590/S0004-282X2011000100012 
18. Kitamura Y, Matsuka Y, Spigelman I, Ishihara Y, Yamamoto $Y$, Sonoyama W et al. Botulinum toxin type a (150 kDa) decreases exaggerated neurotransmitter release from trigeminal ganglion neurons and relieves neuropathy behaviors induced by infraorbital nerve constriction. Neuroscience. 2009;159(4):1422-9. doi:10.1016/j.neuroscience.2009.01.066

19. Welch MJ, Purkiss JR, Foster KA. Sensitivity of embryonic rat dorsal root ganglia neurons to Clostridium botulinum neurotoxins. Toxicon. 2000;38(2):245-58. doi:10.1016/S0041-0101(99)00153-1

20. Meng J, Wang J, Lawrence G, Dolly JO. Synaptobrevin I mediates exocytosis of CGRP from sensory neurons and inhibition by botulinum toxins reflects their anti-nociceptive potential. J Cell Sci. 2007;120(16):2864-74. doi:10.1242/jcs.012211

21. Meng J, Ovsepian SV, Wang J, Pickering M, Sasse A, Aoki KR et al. Activation of TRPV1 mediates calcitonin gene-related peptide release, which excites trigeminal sensory neurons and is attenuated by a retargeted botulinum toxin with anti-nociceptive potential. J Neurosci. 2009;29(15):4981-92. doi:10.1523/JNEUROSCI.5490-08.2009

22. Gazerani P, Pedersen NS, Staahl C, Drewes AM, Arendt-Nielsen L. Subcutaneous Botulinum toxin type A reduces capsaicin-induced trigeminal pain and vasomotor reactions in human skin. Pain. 2009;141(1-2):60-9. doi:10.1016/j.pain.2008.10.005

23. Ranoux D, Attal N, Morain F, Bouhassira D. Botulinum toxin type A induces direct analgesic effects in chronic neuropathic pain. Ann Neurol. 2008;64(3):274-83. doi:10.1002/ana.21427

24. Yuan RY, Sheu JJ, Yu JM, Chen WT, Tseng IJ, Chang HH et al. Botulinum toxin for diabetic neuropathic pain: a randomized double-blind crossover trial. Neurology. 2009;72(17):1473-8. doi:10.1212/01.wnl.0000345968.05959.cf

25. Aurora SK, Winner P, Freeman MC, Spierings EL, Heiring $J$ et al. Botulinum neurotoxin type A for treatment of chronic migraine: pooled analysis of the PREEMPT clinical program 32-week open-label phase. Cephalalgia. 2009;29(Suppl 1):7-8.

26. Piovesan EJ, Teive HG, Kowacs PA, Silva LL, Werneck LC. Botulinum neurotoxin type-A for primary stabbing headache: an open study. Arq Neuropsiquiatr. 2010;68(2):212-5. doi:10.1590/S0004-282X2010000200011

27. Wu CJ, Lian YJ, Zheng YK, Zhang HF, Chen Y, Xie NC et al. Botulinum toxin type $A$ for the treatment of trigeminal neuralgia: results from a randomized, double-blind, placebo-controlled trial. Cephalalgia. 2012;32(6):443-50. doi:10.1177/0333102412441721

28. Morenilla-Palao C, Planells-Cases R, García-Sanz N, Ferrer-Montiel A. Regulated exocytosis contributes to protein kinase $\mathrm{C}$ potentiation of vanilloid receptor activity. J Biol Chem. 2004;279(24):25665-72. doi:10.1074/jbc.M311515200

29. Linde M, Hagen K, Salvesen $\varnothing$, Gravdahl GB, Helde G, Stovner LJ. Onabotulinum toxin A treatment of cervicogenic headache: a randomized, double-blind, placebo-controlled crossover study. Cephalalgia. 2011;31(7):797-807. doi:10.1177/0333102411398402

30. Aurora SK, Gawel M, Brandes JL, Pokta S, Vandenburgh AM. Botulinum toxin type a prophylactic treatment of episodic migraine: a randomized, double-blind, placebo-controlled exploratory study. Headache. 2007;47(4):486-99. doi:10.1111/j.1526-4610.2006.00624.x 